\title{
Androginia e intertextualidad tarótica en El milagro
}

\author{
Androgyny and tarotic intertextuality in El milagro \\ Ronald Antonio Ramírez Castellanos \\ Universidad de Oriente, Facultad de Humanidades, Departamento de Letras, Santiago de Cuba,
Distrito José Martí, Cuba. Correo electrónico: ronald@fch.uo.edu.cu
}

\begin{abstract}
El presente estudio examina el componente mítico en la novela El milagro de Miguel de Carrión, vinculado a la temática de la androginia y su relación, desde un enfoque icónico como procedimiento del análisis semiótico, con el esoterismo tarótico, en tanto elemento de la intertextualidad de la obra. Indagaciones referidas a estos tópicos han sido poco exploradas por estudiosos de la narrativa de uno de los más importantes autores del período republicano en Cuba durante el siglo XX. De esta forma, se logra una novedosa praxis interpretativa como modo de acercamiento a las obras de Carrión, que complementa y redimensiona la trascendencia ideoestética de su producción literaria.
\end{abstract}

Palabras clave: Miguel de Carrión, mito, androginia, tarot, literatura cubana

The present study examines the mythic component in the novel El milagro by Miguel de Carrión, linked to the theme of androgyny and its relationship, from an iconic approach as a method of semiotic analysis with tarotic esotericism, as an element of intertextuality of the work. Inquiries concerning these topics have been little explored by scholars of the narrative of one of the most important authors of the Republican period in Cuba during the twentieth century. Thus, it is achieved a novel interpretive praxis as a mode of approach to the works of Carrion, supplementing and resizes the ideo-aesthetic significance of his literary output.

Key words: Miguel Carrion, myth, androgyny, tarot, Cuban literature

\section{INTRODUCCIÓN}

En el grupo de escritores de la primera promoción del período republicano, generación de tránsito entre dos etapas importantes en el proceso de formación de la literatura nacional -los años finiseculares del XIX e iniciales del XX-, adquiere un lugar meritorio en la historiografía literaria insular la producción narrativa de Miguel de Carrión (1875-1929). Su destacada trayectoria como intelectual se concentra en las tres primeras décadas del siglo XX, alternando indistintamente su profesión en el periodismo con la publicación de casi medio millar de artículos y crónicas en los 
principales rotativos y revistas culturales y literarias de la capital cubana, tales como Libertad, El Comercio, La Discusión, Azul y Rojo, Letras, El Sol, El Fígaro, La Lucha, Heraldo de Cuba, La Noche y Bohemia, por sólo mencionar algunos; destaca también como pedagogo, cuyos aportes significativos se ubican en la implementación de reformas educativas en los distintos niveles de enseñanza, en particular en la instrucción primaria y al frente del plantel normalista de La Habana, a partir de 1926 y hasta 1928; también sobresale en la medicina, pues como galeno sus investigaciones fueron pioneras en la introducción en el país de los novedosos adelantos científicotécnicos para la lucha contra las patologías cancerosas en la Casa de Salud del Centro de Beneficencia y en el Instituto Urológico de la capital cubana y; finalmente, como escritor se destaca en el género narrativo, con cuentos y novelas que actualmente constituyen importantes contribuciones al desarrollo de la literatura insular del período.

La investigadora Mercedes Pereira Torres, profesora de la Universidad de La Habana, ya fallecida, y una de las más recurrentes estudiosas de la narrativa de Miguel de Carrión en la historiografía literaria de la isla, ha ofrecido una propuesta peridiológica que clasifica toda la producción ficcional de este autor en dos etapas fundamentales. La primera ubica los textos que pertenecen al período de juventud (1902-1904), en las que relaciona la novela El milagro (1903), el volumen de relatos La última voluntad (1903) que incluye los textos "La última voluntad", "El doctor Risco", "En familia", "De la guerra" e "Inocencia", asimismo, a este lapso corresponden los textos "Alma de bronce" y "Un escrúpulo", ambos de 1903, y el relato "Un contraste" (1904). En el segundo período (1912-1929) se ubican las siguientes: "Un pedazo de alma" (1912), las novelas Las honradas (1917) y Las impuras (1919), "Astros y besos" (1919), "El error" y "El viudo" de 1921, "El hijo único" (1922), "Noche buena" (1924) y "La noche virtuosa de Don Juan" (1929), así como su novela La esfinge (1961), las dos últimas de publicación póstuma. Esta periodización es un aporte válido asumido por otros exégetas en investigaciones medulares sobre la prosa imaginativa carrioniana.

Vale destacar que toda esta obra ha sido examinada desde diversos puntos de vista por la historiografía literaria cubana: el análisis del discurso narrativo y líneas temáticas, que incluye, como novedad, el acercamiento desde el punto de vista linguo-estilístico, sobre todo en las novelas más conocidas de este autor: Las honradas, de 1917, y Las impuras, de 1919; el componente filosófico y su incidencia en el proceso de formación de la nacionalidad cubana; el contexto histórico de sus obras; el análisis formal desde la perspectiva del personaje, en particular, los femeninos, según los códigos escriturales de la narrativa carrioniana; la recepción crítica de los textos, desde un enfoque evolutivo que abarca desde la época contemporánea al autor, hasta los años iniciales del período revolucionario, y; el examen comparativo con la producción ficcional de otros autores de la primera generación republicana. Estas dilucidaciones contribuyen a un cabal conocimiento de la dimensión y trascendencia de la prosa imaginativa del médico escritor, en una etapa de vital importancia para el desarrollo de la literatura insular, pero no agotan del todo las perspectivas de recepción. Sobre este asunto, la crítica literaria ha hecho énfasis en la necesidad de valorar el legado artístico de autores tan distantes en el tiempo, como Carrión, desde enfoques más novedosos, con el propósito de reactualizar las miradas analíticas al calor de las teorías más contemporáneas.

A lo largo del tiempo, la crítica literaria ha privilegiado el estudio de las dos novelas más emblemáticas de este autor, Las honradas y Las impuras, por sus indudables méritos y calidades artísticas. Sin embargo, este hecho ha propiciado que 
otra de sus obras que, a mi juicio, es muy importante en su trayectoria como escritor, El milagro, haya sido relegada, a pesar de las resonancias y la favorable acogida que tuvo en el momento de su aparición y, por ese motivo, sea en la actualidad menos conocida por el público lector cubano contemporáneo.

Escrita entre noviembre de 1897 y agosto de 1898 -en su etapa como exiliado en los Estados Unidos-, durante el período de la última contienda independentista contra el colonialismo español, El milagro demoró hasta 1903 para ver definitivamente la luz en una imprenta de la ciudad habanera. Al publicarse, Carrión sentaba pautas para el desarrollo de la novela de tema psicológico adscrita a la corriente naturalista, estéticas predominantes en toda su prosa imaginativa. Sobre la obra, el filósofo e ilustre intelectual cubano Enrique José Varona afirmó:

Es un libro en que todo me ha sorprendido; la edad del novelista, el vigor de su concepción, la sutileza de su análisis psicológico, su facultad pictórica, la amplitud y firmeza de su estilo. No sé, en verdad, si a los veintiún años ningún otro autor cubano ha producido una obra de arte de tanto aliento y tan singular relieve. En esta novela es original todo lo que debe serlo (...) Lo son los personajes, el cuadro y la acción (...) El milagro (...) es un libro muy complejo y que puede mirarse y admirarse por muy varias facetas (Cit. en Romero 2011: 368-369).

No obstante, a pesar de estas favorables repercusiones de público y crítica, las miradas posteriores que tuvo la novela por parte de los más notables estudiosos de la obra carrioniana no ofrecen un positivo justiprecio cuando se trata de evaluar la calidad estética de El milagro. Pereira (1978: 12), por ejemplo, aunque reconoce el valor lírico del texto, sustentado en la presencia de abundantes metáforas, imágenes artísticas y, además, el tono poético que hacen de esta novela distintiva del resto de la producción literaria del médico escritor, en su criterio personal, considera a sus personajes carentes de significación para el desenvolvimiento de la trama, a la que califica de monótona y sin acción en diversos pasajes. Asimismo, le resta importancia a la impronta del personaje femenino de la obra, Jacinta, de notoria concepción simbólica, y cuya influencia en el desempeño del protagonista masculino es relevante a lo largo de la diégesis. Según su criterio, los méritos de El milagro se reducen apenas al estilo y a los matices enriquecedores del vocabulario empleado por el autor, que le imprimen al texto un tono poético en su descriptivismo naturalista, y a la caracterización psicológica del personaje protagonista masculino.

Conviene señalar que, hasta el presente, éste y otros escasos estudios sobre la obra citada no advierten las referencias simbólicas y mitopoéticas que revisten a El milagro de un inusitado esteticismo dentro de la producción literaria del autor de Las honradas y Las impuras. De ahí que una posibilidad de recepción del componente ideoestético del texto -y de la narrativa toda de Miguel de Carrión-, radica en el análisis de dichas referencias míticas. En efecto, una lectura indagadora permite confirmar la presencia de un sustrato mitológico referido a los tópicos concernientes a las problemáticas socioculturales de la mujer, desde el punto de vista ético, moral, estético, espiritual, biológico y sexual, en correspondencia con los códigos escriturales implementados por el autor, perceptibles tanto en el plano ideotemático como composicional de sus obras (por ejemplo, Las honradas, Las impuras, La esfinge, "Alma de bronce", "En familia", "El error", "Noche buena", etc.), y por otro, a los mitos referidos a 
temáticas universales, tales como el héroe, la heroína, el amor, la sexualidad y la visión cosmogónica del mundo, en los cuales se articula un componente filosófico influido por las teorías positivistas de ascendencia en Nietzsche, que le permiten al autor desarrollar en sus textos narrativos ficcionales su tesis de la ley de atracción de los opuestos, que convergen en la unidad dual complementaria, fundamento de la androginia. Este componente mítico predomina, sobre todo, en la prosa imaginativa del primer período de su producción literaria, en particular, en su novela El milagro.

Es por ello que, desde este aspecto, el presente trabajo tiene como propósito ofrecer un acercamiento a esta obra potenciando otras aristas interpretativas del texto, desde un enfoque no efectuado hasta el presente por la crítica literaria estudiosa de la narrativa de Miguel de Carrión. Con ello intento responder a las necesidades de profundizar, desde las ciencias literarias, en los estudios sobre los vínculos exegéticos entre los mitos y la literatura cubana, en particular en los textos de ficción carrionianos, como respuesta a los reclamos efectuados por la crítica y la historiografía literaria del país.

\section{El mito del andrógino y Su Relación Con el esoterismo tarótico: Preliminares TEÓRICAS}

En la narrativa de Miguel de Carrión, un aspecto significativo a ponderar lo constituye el tratamiento ficcional de la temática de la sexualidad y las relaciones amorosas, muy vinculadas a los mitos heroicos. Sobre este asunto, la investigadora Cira Romero ha destacado que "las tesis fundamentales propuestas en su obra novelística, centradas en que el amor es la fuerza esencial que promueve los valores espirituales del hombre y en que la unión de dos seres debe efectuarse a partir de las afinidades que brindan la mutua comprensión y el deseo, le confieren a su obra una preeminencia que se desenvuelve a través de la antinomia del bien y del mal" (2003: 139).

En la anterior afirmación la analista no sólo alude al caudal mitopoético que sustenta justamente la estética discursiva de la aventura mítica; advierte también un constructo simbólico intertextual convergente con la temática de la androginia. Este mito arcaico condensa un sustrato filosófico relacionado con la mística erótica, en el cual la coexistencia de los contrarios, macho y hembra, principios cosmológicos opuestos, símbolos del poder solar masculino y lunar femenino, respectivamente, apelan al matrimonio sagrado en su búsqueda de la perfección, la plenitud restauradora del orden espiritual, la armonía y el equilibrio:

El poder solar masculino se abre camino en el mundo por medio de su presión egoísta y racional convirtiéndose, cada vez más, en algo distinto y difuso hasta que encuentra su opuesto, el lunar, femenino, intuitivo o instintivo, con quien se relaciona y, finalmente, se integra en la unión matrimonial. Esta es la conjunctio de la Alquimia, en la que lo masculino y lo femenino, el Rey y la Reina, se fusionan en la unidad final, el estado en que ya no existen oposiciones del Andrógino, el Centro. Esta búsqueda de una verdadera pareja tiene lugar en todas las alegorías míticas y religiosas, es la búsqueda personal mediante la relación y la participación, la disolución de los contrarios (...) (Cooper 1998: 93).

Estos fundamentos particularizadores del mito del andrógino encuentran resonancias muy significativas en los preceptos filosóficos de carácter positivista, emparentados con el existencialismo nietzscheano, que Carrión plasmará a lo largo 
de su producción literaria, en textos como El milagro, "Inocencia", "Astros y besos" o "El viudo"; también en su prosa reflexiva no ficcional, como artículos periodísticos, máximas filosóficas y otras anotaciones aún conservadas en su papelería inédita.

En un artículo publicado en la revista Azul y Rojo de La Habana, a propósito de la polémica desatada en el país en torno a la ley del divorcio, Carrión subordinaba, desde este punto de vista, la función del individuo en la sociedad a la actividad reproductiva con el propósito de perpetuar la especie, según los principios de la selección natural; tesis ya desarrollada poco antes en su novela El milagro, como crítica al celibato forzado del hombre, impuesto por el dogmatismo religioso cristiano. Aunque aceptaba la posibilidad del amor libre como alternativa en la praxis de las relaciones sexuales, en el fondo era partidario de la indisolubilidad del matrimonio como pretexto para conservar incólume la estabilidad de la familia, en correspondencia con el mandato ancestral que obedece al instinto, la voluntad y la pasión, nucleados en la ley de atracción de los opuestos:

El individuo no es un ser completo hasta el instante en que paga su débito a la naturaleza en buena moneda de amor. De aquí que el más monstruoso de los crímenes sociales sea el celibato, y mucho más reprochable que el suicidio, porque no tiene como este la excusa del arrebato momentáneo. El amor, por lo tanto, es más fuerte que el instinto de conservación personal, el cual queda anulado muchas veces en presencia del interés triunfante de la especie (...) Con estas verdades hábilmente manejadas han forjado los defensores de la indisolubilidad un arma formidable contra la reacción del contrato del matrimonio. ¿No es esta la ley de la naturaleza? ¿Qué tiene, pues, de injusto, que si los caracteres no armonizan, si la dicha no se encuentra y la vida individual naufraga el hombre y la mujer continúen unidos, no ya para amarse, sino para mantener intacta la unidad de la familia? (1903: 14).

La asimilación de las corrientes filosóficas modernas de la época le permitió a Carrión concretar su concepción positivista del mundo y la sociedad, sustentada en la eternidad de las fuerzas naturales, la inexistencia de una inteligencia supraterrenal creadora del universo y de la actividad del hombre, esta última, marcada por una praxis mecanicista de la evolución social, criterios ya señalados en diversas ocasiones por los estudiosos de su pensamiento científico-filosófico y de su obra literaria. En otros de sus artículos publicados en la revista habanera Letras, estos basamentos son utilizados como herramientas para interpretar la realidad cubana de la época, signada, desde su punto de vista, por el caos de las fuerzas gubernamentales desequilibradoras de las individualidades fragmentadas (las clases) que conforman el todo indisoluble $\mathrm{y}$, con ello, impiden la organización social:

En todo organismo la vida es producto de millares de energías que concurren en un fin, y lo que se exterioriza es solo un resumen del trabajo lento y profundo de las individualidades que integran el todo. Si no hay unidad de tendencias, si el desequilibrio no existe o se rompe en un momento dado, la organización entera sufre; pero cuando se trata de proponer el remedio es menester buscar las causas del mal mejor que en el conjunto en los elementos que lo forman (1910: 2).

En teoría, Carrión consideraba como solución a esta problemática social el papel del Estado en la formación del carácter del individuo. En particular, subordinaba el 
desempeño de la mujer en la educación de los futuros componentes de una sociedad que debía aspirar a su perfección, a estos preceptos positivistas de nuevo tipo, en nada divergentes con las teorías ruskinianas decimonónicas en torno a la división de las esferas, según las cuales, de acuerdo con María del Carmen Barcia,

el varón tenía su papel social en la esfera pública de la producción y la política, en tanto la mujer debía desenvolverse en el espacio doméstico. Esta especulación implicaba una manera de pensar y preservar la división sexual del mundo y de organizar «racionalmente» tareas y espacios, reconciliando la vocación natural con la utilidad social (2009: 299).

De este modo, la función social de la mujer y su proyecto de vida se limitaba a un complemento armónico mediante su unión al hombre. En correspondencia con la exégesis mítica del andrógino, su tarea más importante en la indisolubilidad de los opuestos consistía en su actividad regeneradora del orden moral, relacionada con la educación del individuo encargado de la institucionalización de la familia, la sociedad y la dirección del Estado. Esto involucraba, evidentemente, una vigorización del discurso de la domesticidad en el que el mito de la mujer destinada al amor, a la reproducción y a la perpetuación de la especie dependían, según Carrión, de la necesidad de mantener inamovibles los patrones educativos que limitaban el desarrollo ético, moral y espiritual de la mujer.

En la medida en que tales criterios políticos, filosóficos, sociológicos, éticos y estéticos del positivismo carrioniano, vinculados a la androginia, se traducen en naturalismo literario, la mujer no sólo se transforma en finalidad del hombre y su complemento indisoluble, también ocupa el vacío propiciado por la inexistencia de la divinidad gestora y regente de las leyes del universo. Por ende, adquiere una dimensión simbólica de espiritualidad, que contrasta con sus atributos y significaciones terrenales, sedimentados en el imaginario colectivo.

En tal sentido, la exégesis mítica de la androginia, componente de la intertextualidad en las obras mencionadas, admite ser analizada en su vínculo con el esoterismo tarótico, lo cual posibilita una perspectiva otra de acercamiento en el proceso hermenéutico, en correspondencia con las claves puestas en juego por el autor, hasta el presente no efectuada por la crítica literaria. Esta óptica incluye, por obligatoriedad, el enfoque icónico como técnica de interpretación en el procedimiento semiótico, desde la proyección imaginal indirecta, una dilucidación científica orientada al análisis de los textos literarios. Es útil recordar lo planteado por Luis Álvarez Álvarez sobre este particular:

La investigación con enfoque icónico, sin dejar de tener en cuenta elementos del análisis semiótico, se ocupa de todos los factores y procesos que influyen de manera determinante en la conformación del significado en una obra artística (...) La icónica, por tanto, es un enfoque de análisis que aspira a ir más allá del texto específico de la obra de arte -su semántica, su estructuración, sus funciones-, y a focalizar también para decirlo en términos semióticos- los textos que subyacen bajo aquel, vale decir, los subtextos -artísticos, pero también culturales en sentido amplio- (...) La perspectiva icónica del análisis del contenido de la obra de arte, trasciende, pues, el texto nuclear (2010: 238-239). 
Por lo anterior, se propone atender la significación simbólica de la lámina del sexto arcano del Tarot en dos de sus representaciones icónicas conocidas, la de Marsella (Figura 1) y la Egipcia (Figura 2), pues, en tanto textos icónicos, convergen en el plano composicional e ideotemático con las obras citadas. 1) En el plano composicional: se observan semejanzas en cuanto a la caracterización etopéyica y prosopográfica de los personajes que integran la figura icónica, y los de los textos narrativos ficcionales, en específico, los femeninos en sus representaciones ambivalentes de significación. 2) En el plano ideotemático: en su nivel connotativo, se aprecian convergencias con las ideas filosóficas del pensamiento carrioniano, relacionadas con la ley de atracción de los opuestos, integrada en la unidad dual complementaria; síntesis del mito del andrógino trasladado a las obras narrativas.

Este paralelismo tiende a legitimar un enfoque interpretativo (icónico) amparado en las posibilidades que brinda la hermenéutica textual simbólica, como praxis de la semiótica aplicada al texto literario. En este orden, Gerard Encausse, importante estudioso de este sistema de signos, en su libro El tarot de los bohemios, define que el simbolismo del sexto arcano expresa "ideas de antagonismo en todas sus consecuencias" (2006: en línea), un elemento caracterizador de la androginia.

Figura 1: "El Enamorado"

(Tarot de Marsella)

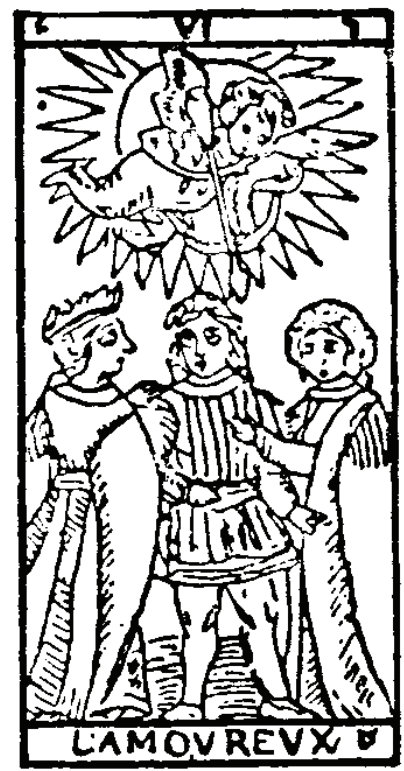

Figura 2: "La Indecisión"

(Tarot Egipcio)

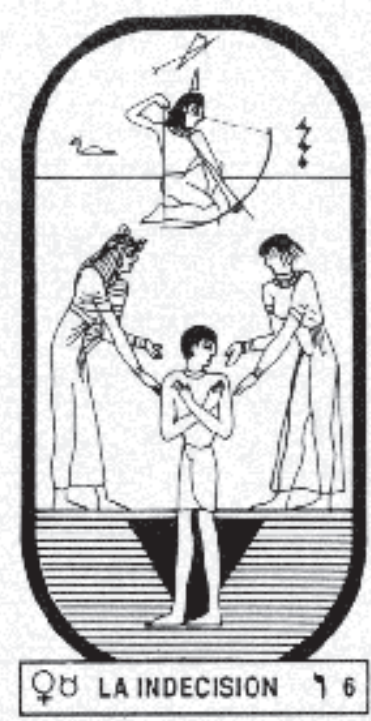

Las láminas están compuestas por cuatro figuras representativas. La primera es un personaje masculino con sus brazos cruzados al pecho en posición diagonal, inmóvil ante una encrucijada, pues ignora el camino que oriente de forma acertada y dinámica "el magnetismo de su astral" (Aun Weor 2006: en línea). Para el Tarot Egipcio, este arcano se nombra "La Indecisión", pues el héroe mítico se enfrenta a la disyuntiva 
de elegir la vía más adecuada en su tránsito por la vida. Como se observa, aparece acompañado por dos mujeres, personajes clave que influirán, de forma constante, en la futura elección del sujeto masculino. La ubicada a la derecha simboliza la espiritualidad, la virtud, lo divino; la figura femenina de la izquierda, denominada la Medusa, la Ramera o la Mujer Terrenal, representa lo opuesto: el libre albedrío, el vicio, la tentación, las pasiones carnales en sus diversos grados de representación.

Para Samael Aun Weor (2006: en línea), especialista en las ciencias cabalísticas y esotéricas, es también el yo psicológico, el inconsciente particular de cada individuo, el que se ve representado en estas figuras. Sobre esta última, el personaje central del arcano siente una particular atracción, de ahí que su rostro permanezca observando el lado izquierdo. En la parte superior de la lámina aparece la cuarta figura, el genio de la justicia o jerarca de la ley, símbolo de la conciencia, una especie de dios alado que apunta con la flecha del castigo hacia la figura femenina del lado izquierdo, representativa de las pasiones terrenales.

En sentido general, el simbolismo del arcano concreta dos posibilidades de lectura: 1) si el hombre elige el camino de la virtud (figura femenina del lado izquierdo), será ayudado por la providencia para vencer las fuerzas contingentes del mal, las llamadas pruebas calificantes de la saga heroica, y con ello alcanzará el sentido de realización espiritual; 2) si el hombre elige el camino del antagonismo (lucha violenta entre las pasiones y la conciencia) transmutado en amor, emergerá la unión de los opuestos, lo cual para el héroe mitológico constituye una fuerza poderosa. Esta perspectiva de lectura introduce otra de las denominaciones del arcano: "El Enamorado" (Encausse 2006: en línea).

Además de los valores afectivos, esta figura icónica, como indica Chevalier (1986: 443-444), simboliza la proyección de la doble imagen que el hombre se hace de la mujer, una clara referencia a los mitos dualistas: por un lado, la divinizada (lado derecho del arcano en su aspecto positivo), que inspira el amor contemplativo, platónico; por otro, la terrenal (lado izquierdo negativo), símbolo del amor carnal, ambas figuras complementarias, a su vez, de una misma expresión simbólica: el arquetipo de la Diosa Madre ${ }^{1}$.

En el lenguaje gráfico de la mitología, Campbell reconoce que esta representación ambivalente del simbolismo de la imago mujer es para el héroe mítico “(...) la totalidad de lo que puede conocerse. El héroe es el que llega a conocerlo. Mientras progresa en la lenta iniciación que es la vida, la forma de la diosa adopta para él una serie de transformaciones (...) Ella lo atrae, lo guía, lo incita a romper sus trabas" (1959: 110). En el encuentro del héroe con la Diosa radica el matrimonio místico-sagrado: la prueba glorificante considerada la de mayor importancia en el ciclo de la saga heroica.

En los cuentos populares o maravillosos como el de "La Bella Durmiente", por ejemplo, dicho encuentro se interpreta como la proyección inconsciente del alma masculina (el héroe o el príncipe) encarnada en cada mujer. Esta elucidación hermenéutica de los simbolistas y los integrantes de la escuela del psicoanálisis,

\footnotetext{
Los aportes de C. G. Jung en torno a las “imágenes arquetípicas” fueron adoptados por los más diversos teóricos para explicar el simbolismo mediante el cual se expresa el pensamiento irracional, debido a su factible aplicación, desde otras aristas epistémicas, para el estudio y comprensión del imaginario cultural universal. Para Jung, las imágenes arquetípicas conforman un espectro onírico, fantasioso, de motivos recurrentes y universales, manifestado, en un principio, en el discurso religioso y mítico, comportando un carácter autónomo, más tarde trasladado a los diversos géneros literarios, en tanto reflejo del inconsciente cultural colectivo.
} 
apoyada en la teoría de los arquetipos del animus y su contrario, el anima ${ }^{2}$, elaborada por Carl Gustav Jung, ha servido para estudiar de forma rigurosa y eficaz muchas de estas historias que emplean con marcada recurrencia el tema del alma externada o separable. Según este analista, la unión de ambas representaciones arquetípicas permite la concreción final del self $^{3}$, es decir, la unidad dual de vuelta al centro que propició su origen, denominada coincidentia oppositorum. A los efectos de esta investigación, esto es clave como herramienta para el análisis de la exégesis mítica de la androginia, y su relación con el simbolismo del sexto arcano del Tarot.

De acuerdo con las preliminares teóricas anteriores, analizaremos el mito en la novela El milagro, tomando como referencia las convergencias de su exégesis con el significado simbólico de la sexta lámina del Tarot "La Indecisión" (Tarot Egipcio) o "El Enamorado" (Tarot de Marsella). Ajustado a los límites que rige esta investigación, privilegio aquellos elementos narrativos que permiten destacar el simbolismo mitopoético de sus personajes protagonistas.

\section{ANÁLISIS DE LA NOVELA}

La trama de El milagro narra la historia de Juan, un adolescente que ha crecido bajo la custodia de su padre, un próspero hacendado de la región ficticia de X. Años atrás, al nacer, había muerto la progenitora del joven, por lo que este suceso alimentaría en él cierta idea de culpabilidad. Los primeros años de su infancia y adolescencia transcurren en el agreste valle, lugar donde se ubica, además, un poblado de escasos habitantes. El recuerdo de la madre fallecida, a quien Juan evoca constantemente, norteará las acciones de éste, quien, a toda costa, intentará mantener incólume su pureza, aún no contaminada con el provincianismo vulgar y las costumbres de los equisteños, entregados, en muchos casos, a una vida licenciosa. Es por ello que el joven protagonista decide ingresar en un seminario e iniciar una carrera eclesiástica, motivada por una aparente vocación religiosa. Sin embargo, la llegada a la casa de su prima Jacinta, transformada prontamente en una atractiva mujer, sirve de pretexto para desencadenar en el joven un conflicto existencial que será el tema fundamental de toda la trama: por un lado, el de permanecer fiel a los preceptos religiosos que ha recibido en el seminario y a la memoria de la madre muerta, a quien ha consagrado todos sus ideales de pureza; por otro, el de ceder a la irresistible atracción sexual que siente cada vez por Jacinta, quien, a su vez, demuestra reciprocidad en sus sentimientos de amor por Juan, el enamorado indeciso.

Anima y animus son complejos personificados reconocidos como relativamente autónomos. Jung dedica un vasto estudio a estos arquetipos en El yo y el inconsciente (1955) y en Tipos psicológicos (1950). "El anima es el aspecto femenino presente en el inconsciente colectivo de los hombres y el animus es el aspecto masculino presente en el inconsciente colectivo de la mujer (...) El anima puede estar representada (personificada) como una joven chica, muy espontánea e intuitiva, o como una bruja, como la Madre Tierra. Usualmente se asocia con una emocionalidad profunda y con la fuerza de la vida misma. El animus puede personificarse como un viejo sabio, un guerrero o usualmente un grupo de hombres (...)" (Boeree 2012: en línea).

3 El arquetipo del self(sí-mismo), al igual que el del animus, anima, sombra y persona, son los que más han alcanzado desarrollo en el imaginario colectivo. Con respecto al self se plantea que: "es un arquetipo que representa la trascendencia de todos los opuestos de manera que cada aspecto de la personalidad de un individuo es expresada de forma equitativa. Por tanto, no somos ni masculinos ni femeninos, somos ambos; lo mismo para el yo y la sombra, para el bien y el mal, para lo consciente y lo inconsciente, y también lo individual y lo colectivo (la creación en su totalidad) y por supuesto, si no hay opuestos, no hay energía y dejamos de funcionar. Evidentemente, ya no necesitaríamos actuar" (Boeree 2012: en línea). 
En El milagro, la tríada simbólica de este arcano aparece representada por Juan, el protagonista: él es el personaje masculino del centro, decidido a tomar el camino de la fe divina al manifestar su vocación por la vida monástica. Al mismo tiempo, se siente atraído por las dos figuras femeninas que en el texto ejercen su marcada influencia sobre su futura elección: la madre muerta, por un lado, símbolo de la imago femenina divinizada (camino de la Fe); por otro, el personaje Jacinta, la mujer terrenal (expresión simbólica del camino de la Razón).

En la primera secuencia narrativa del texto se destacan, a través de los atributos prosopográficos y etopéyicos del héroe, las alusiones a su estado inicial de pureza y su estrecha conjunción con el código topológico, de notoria naturaleza mística. La orfandad, rasgo muy común en los protagonistas de las sagas mitológicas, distingue a Juan, pues su madre había muerto poco después del parto. No obstante, tanto la carencia de lo materno como la poca afectividad de la figura del padre, son suplidas por el abrazo de la madre natura (arquetipo de la Diosa representado simbólicamente por el código topológico en la diégesis) que lo acoge en su seno:

La naturaleza, por su parte, habíase encargado de echar sobre él la sombra misteriosa de sus bosques, el olor áspero de sus resinas, el suave perfume de sus guirnaldas silvestres, todos sus encantos y todas sus durezas (...) Una madre no es más que una débil partícula de la naturaleza que refleja momentáneamente parte de las bellezas que ésta encierra. Él tenía para sí a la madre de todas las madres. Tenía sobre su frente un firmamento lleno de luz, y bajo su planta un mundo lleno de vida (1976: 53) ${ }^{4}$.

En esta parte inicial del texto, sus elementos simbólicos aluden a los aspectos semánticos positivos de la lámina del sexto arcano del Tarot, y con los cuales el héroe mítico se manifiesta inicialmente identificado. La imagen de la madre muerta, por ejemplo, representante de la fe y la espiritualidad, influye en el pensamiento de Juan y en las acciones que determinan su conducta:

Todas las cualidades verdaderas de la madre se hicieron perceptibles en Juan, a medida que los meses pasaban (...) Al parecerse cada vez más a la mujer de quien había nacido, el niño sintió nacer en su corazón una ternura sin límites hacia la muerta, a la cual se sentía atraído por una simpatía nueva, que en lo sucesivo había de desempeñar un gran papel en su vida (p. 71).

También se aprecia, en el eje de la verticalidad espacial, el sentido de antagonismo mediante la oposición binaria positivo-negativo que el narrador otorga al código topológico: el cielo, lugar en donde se alude a la presencia espiritual de la madre muerta, simboliza el lado positivo de la lámina, y lo contrario es la tierra, el valle de $\mathrm{X}$, región última en la que trascurre la primera parte de las acciones narrativas (etapa de adolescencia de Juan), y con la cual el héroe mítico no se identifica: “Aquella fuerza inmensa que se acumulaba en él al advenimiento de la pubertad buscaba un espacio donde explayarse. Más allá de X y del mundo había un cielo a la codicia humana, una jerarquía más alta, una vida eterna en medio de goces (...) Juan conocía a X y al cielo, y se decidió por este último" (p. 72).

Todas las referencias a la novela son extraídas de la edición de 1976. En adelante, sólo se consignará entre paréntesis el número de las páginas que corresponden al fragmento citado. 
Es importante destacar que con la entrada de Jacinta en la historia, su constante influencia tentadora introduce la problemática de la indecisión (exégesis del arcano), y la primera transformación del héroe mítico y su entorno. En el caso de Juan, desde el punto de vista etopéyico y prosopográfico, dicha transformación es física y espiritual. Con respecto al cambio semántico del espacio natural, la sutil focalización de la mirada introspectiva del yo-psicológico del héroe mítico ofrece algunos matices caracterizadores: para Juan, X, el valle, ya no denota la imagen de "agreste grandeza" ni el aspecto "de un colosal anfiteatro en ruinas" (p. 40), sino valores semánticos positivos, atractivos al héroe. Por lo tanto, generan en su pensamiento un sentido ambivalente y de indecisión, debido a la influencia del personaje de Jacinta: "Nunca el sol había tenido un brillo tan intenso, ni los árboles una sombra tan fresca ni la creación entera una voz tan elocuente en el conjunto de sus millares de armonías diversas" (p. 84).

Mediante el uso de una descripción meticulosa, es perceptible la enfática alusión a uno de los mitos más conocidos por la extensa iconografía simbólica del discurso religioso judeo-cristiano: el mito bíblico de la creación, Adán y Eva en el paraíso antes de la trasgresión pecaminosa y el posterior castigo divino que conllevó a sus expulsiones del Edén. La relación de esta exégesis mitopoética con la androginia, como se conoce, es intrínseca. En El Milagro, la alegoría trasciende en el sentido de complementariedad de Jacinta-Eva para Juan-Adán. X, ahora con sus atractivos naturales, es el paraíso que el protagonista descubre a los ojos de Jacinta-Eva con "mutuas explosiones de júbilo".

En esta etapa de la diégesis mítica se vislumbran tres aspectos fundamentales. En primer lugar, la junción de nuevos lexemas a la cadena isotópica que alude al simbolismo de la unidad trinitaria en la praxis religiosa judeo-cristiana. Si antes la tríada Padre-Hijo-Espíritu Santo podía identificarse en los personajes de Don Lucas, padre del protagonista, en Juan, su hijo, y también en la invocación a la madre muerta, ahora la alusión al símbolo judeo-cristiano aparece semantizado mediante la nueva tríada conjuntiva que conforman Juan-Jacinta y la naturaleza. Esta última, como elemento unificador entre el Juan-Adán y la Jacinta-Eva, propicia una armonía perfecta, libre de impurezas y de pensamientos lascivos, como se advierte en el siguiente pasaje, a modo de ejemplo: "La naturaleza los aprisionaba y los fundía en una sola alma, al soplo de un mismo deseo. A veces sin hablarse, los dos quedaban, durante largo tiempo, sumidos en un éxtasis sagrado; y luego sentíanse más risueños, más satisfechos, más ágiles (...)” (p. 84).

Un segundo aspecto a ponderar radica en el sentido de alteridad complementaria entre Jacinta y Juan, tal y como se expresa en la cita anterior. Ella es su anima arquetípica, referencia implícita a la coniuctio alquimista a la cual alude el mito del andrógino en la diégesis:

Sin ser coqueta, sin darse cuenta ni siquiera de sus actos y aun antes de ser núbil, Jacinta era mujer, toda mujer, y estaba orgullosa de serlo; lo mismo que Juan era hombre, sin sombra alguna de afeminación, a pesar de haber considerado su virilidad como un baldón de la naturaleza. Este fue el secreto de su mutua atracción y de su cariño recíproco (p. 85).

Por último, cabe señalar la asociación de Jacinta con el código topológico, desde la perspectiva del narrador. Estas dos figuras, mujer terrenal y naturaleza, se visualizan 
en esta primera secuencia narrativa positivamente semantizadas. Dicha apreciación permite inferir que la primera parte del texto hace referencia, simbólicamente, tanto por el código topológico como por los personajes, al aspecto positivo del sexto arcano del Tarot.

Como puede leerse más adelante en el texto, los valores semánticos connotativos del simbolismo de la imago mujer, a través de este personaje, adquirirán su expresión negativa, con las transformaciones experimentadas en su etapa de iniciación sexual. Desde la percepción del héroe mítico, la joven resaltará por su belleza tentadora, hecho que desencadena en la diégesis el conflicto interno del protagonista: permanecer fiel a sus preceptos religiosos, honrando la memoria de la madre muerta, o ceder al despertar de sus instintos sexuales, motivado por el influjo tentador de su deslumbrante prima. En otras palabras, la problemática de la indecisión.

En esta etapa de la trama, la caracterización del personaje femenino contiene remanentes simbólicos contrastantes con la significación positiva de la imago mujer divinizada (la madre). En primer lugar, lo prosopográfico, acentuado en el claroscuro (blanco de la piel, negro de las ropas). Como recurso ideoestético, proporciona el efecto resemantizador ambivalente, no sólo del propio personaje, sino también del código topológico. De este modo, la imago femenina terrenal se torna más atractiva a la mirada del héroe, que el modelo connotativo de espiritualidad representado por la madre muerta:

El vestidito negro de Jacinta se enredaba en las espinas de las zarzas, y ella gritaba, riendo como una loca, a su primo, que iba delante, que la habían cogido prisionera y no querían soltarla; él sin volverse, apresuraba el paso, y entonces ella, tirando fuerte, lo desgarraba y reía con más gana. El viento agitaba la falda y las anchas mangas de la niña dándoles la apariencia de negras alas que revoleteaban en torno de su cuerpo (p. 85).

Otro elemento importante de paralelismo con la semantización paulatina hacia la negatividad del arcano, enunciado a través del simbolismo del personaje de Jacinta, se observa en el pasaje sobre su llegada a la casa del anciano filósofo, el eremita Arista, acompañada de Juan. Aquí, en la puerta de la simbólica morada, el narrador advierte la presencia de un mono encadenado que Jacinta se detiene a contemplar. Tanto la acción del personaje como el simio adquieren en la trama un simbolismo importante que no puede pasarse por alto. Para explicar esto, debe retornarse a la escena inicial que relata la estancia de Juan dentro del seminario, y atender allí a su reacción cuando examina el desarrollo de la vida monástica y las relaciones de sus condiscípulos:

El adolescente pensaba, estremeciéndose, en las uniones monstruosas, en los extravíos de la carne que la casualidad le había hecho presenciar entre los colegiales. A veces le parecía que, al volver la cara iba a encontrarse con una de las tremendas obscenidades que le rodeaban (...) Todo brotaba de la misma furia erótica, de las contorsiones grotescas del mono en celo que habita en el pecho de cada hombre, y del torpe deseo de la carne que ignora la existencia de otros goces más duraderos y más intensos ( $\mathrm{p}$. 82 , las cursivas son mías).

La alusión implícita al simbolismo del mono mediante el uso de una metáfora comparativa es marcada, además, después de la escena que narra el sacrificio de 
los pollos, una de las más simbólicas de la novela. Aquí Juan escapa de la tentación sexual que despierta por Jacinta y se refugia en lo alto de una montaña donde, casualmente, un desconocido habitante de X dormita de manera imperturbable: "Un hombre dormía sobre la meseta, a la sombra del árbol, cubriéndose el rostro con el brazo para resguardarse de la luz. La brisa del mar levantaba a intervalos su camisa, y veíase su pecho, moreno y velludo, agitado por una respiración sosegada" (pp. 147-148, cursivas mías). Luego de un instante de profunda introspección meditativa, y recobrada la calma de espíritu bajo la fuerte influencia del recuerdo de la madre muerta que acudía, una vez más, en auxilio al sufrimiento del joven, la mirada de Juan

(...) inflamada por el divino ardor, tropezó de pronto con el cuerpo que yacía en tierra a los pies del caballo, y se tornó desdeñosa. Después abarcó a X entera, con un relámpago de reto, y bajó lentamente la cuesta, erguido sobre la montura en una actitud soberana. El desconocido quedó allí, indiferente y descuidado, bajo la caricia del aire que arrullaba su sueño. Sobre el pecho, que se levantaba con suave ritmo, el vello negro ondulaba, rizado por el viento, como un campo de espigas bajo la racha. Juan no volvió el rostro; pero a pesar de su desprecio, no pudo evitar que aquella imagen quedara fuertemente grabada en su recuerdo (p. 150).

Puede notarse con la descripción física del desconocido, cómo la imagen artística lograda a través de la cadena lexemática destacada en cursivas, permite establecer un campo asociativo que remite al simbolismo del simio, cuyas significaciones en la iconografía mágico-religiosa universal advierte características homogéneas, y al mismo tiempo contradictorias. Este animal es asociado, sobre todo, al desenfreno sexual por su denotado "temperamento ardiente", en tanto expresión de las fuerzas irracionales, no controladas del deseo instintivo. Según Chevalier, constituye, por otro lado, un referente simbólico de los actos determinados por mecanismos que lo inconsciente no puede regular " (...) sea en forma peligrosa, desencadenando fuerzas instintivas, no controladas y en consecuencia degradantes; sea en forma favorable e inesperada (...) Tiene de lo inconsciente el doble aspecto, maléfico a la manera del brujo y benéfico a imagen del hada, pero ambos irracionales por un igual" (1986: 720).

Dentro del espectro iconográfico del cristianismo, y de ello se sirve el texto, el simbolismo del mono constituye "(...) a menudo la imagen del hombre degradado por sus vicios, y en particular por la lujuria y la malicia" (1986: 720). De acuerdo con lo anterior, el mono encadenado en la puerta de la casa del anciano filósofo representa el instinto sexual humano controlado, sin que forzosamente ello signifique una supresión de la líbido. Denota también la balanza entre lo afectivo y lo cognitivo, el instinto y la razón; ambos componentes rectores de la actividad humana, armonizados equilibradamente y en estrecha unión con las fuerzas de lo incognoscible.

Desde este punto de vista, llama la atención el hecho de que sea Jacinta, y no Juan, quien se detenga a "observar" al simio. Este acto contemplativo, como indica el texto, sugiere una asociación indirecta identificativa entre la imago mujer, Jacinta, con el simbolismo del mono. Esto no resulta extraño, pues el discurso religioso judeo-cristiano en las culturas occidentales impuso, desde el surgimiento propio del cristianismo, una política secularizada de "satanización" del sexo femenino. Al mismo tiempo, implantó 
conductas sexofóbicas en su entorno, que contribuyeron a la degradación de su condición social y a su posterior sometimiento a los cánones patriarcales.

Lo anterior permite comprender más adelante en la lectura, con la transformación física de la joven prima, cómo la mirada del héroe mítico conduce a la semantización negativa de la imago mujer. Este hecho justifica la resistencia de Juan a su apasionante atracción por la prima y, en consecuencia, al efervescente desarrollo de su neurosis. En el ciclo de la aventura mítica, Campbell (1959: 114) advierte en esta fase de la diégesis el desempeño del actante mujer como tentadora de las acciones del héroe mitológico. Ella provoca sobre él una influencia desestabilizadora en muchos casos, pero al mismo tiempo útil, pues le facilita su ascensión y consagración moral durante el proceso de iniciación y afrontamiento de las pruebas, a las cuales se somete el héroe mítico.

De este modo, el creciente interés de Juan cataliza en él un proceso neurótico. La resistencia a la tentación anula los instintos sexuales y lo obliga, en diversas ocasiones, a aferrarse al recuerdo de la madre, un aliciente simbólico opuesto a las impurezas de la existencia contaminadora de la espiritualidad y de la vocación religiosa que el héroe insiste en profesar. Es la negativa al llamado a la aventura mítica expresada mediante la pugna entre la razón y la conciencia, en la cual, de manera reiterada, la imago femenina terrenal estimula el erotismo al punto de desencadenar la bestialización del instinto. El pasaje emblemático, en este sentido, lo constituye la escena de Jacinta descuartizando los pollos ante Juan. En el nivel connotativo del discurso, el sacrificio de los animales se equipara con la carne de la mujer; los cuchillos empleados, atributos fálicos, con el órgano sexual masculino del protagonista. Éste, mientras asiste a la inmolación de las aves, no puede evitar su despertar sexual al extremo de recrearse, placentero y sobresaltado, hasta el paroxismo de dimensiones morbosas.

En este punto clímax de la acción, el narrador introduce una relación causal, casi mágica, entre Juan y el código topológico, para simular el orgasmo masculino; hecho que anuncia de manera implícita la toma de conciencia definitiva del héroe obcecado por sus instintos. De ahí, hasta la escena en que espía a Jacinta a través de la cerradura de la puerta del cuarto, su percepción de la mujer denotará matices menos cruentos y más sutiles, a tono con un erotismo sensual y refinado. A esto debe añadirse que en sus últimas escapatorias, huyendo de la tentación, sus pensamientos evocarán una imagen de la madre muerta cada vez menos nítida.

Con la concreción de la pasión amorosa y la unión de ambos personajes, mediante el acto sexual anhelado por ambos, el conflicto planteado por la indecisión, cede a la atracción de los opuestos. Éstos, en tanto fuerzas complementarias, se integran como una unidad indisoluble, mística, bajo el amparo nocturnal de la aridez del camposanto, lugar escogido por el autor implícito para desarrollar la última escena de la novela, al que le otorga una connotación semántica regeneradora, de ascensión espiritual, de convergencia con la unidad divina y universal del arquetipo de la diosa, simbólicamente representada por la Madre Tierra:

(...) los dos cuerpos rodaron por tierra, bajo una lluvia de pétalos rotos (...) Bajo el dosel más rico que pueda cobijar los amores humanos celebráronse las nupcias de los elegidos; cumplíase la obra regeneradora de la buena tierra de X, y a impulsos del amor inmortal, inútilmente calumniado, brotó y cayó sobre ella el rojo de la virginidad, única ofrenda digna de la Madre (p. 292). 


\section{CONCLUSIONES}

La narrativa de Miguel de Carrión, escritor de la primera generación republicana en las letras cubanas del siglo XX, adscrito a la tendencia naturalista y psicológica, presenta un sustrato mítico de características peculiares que destaca un diseño simbólico de sus personajes femeninos. El acercamiento a la novela El milagro, desde procedimientos propios de la hermenéutica textual simbólica, posibilitó un nuevo enfoque interpretativo que reactualiza los criterios emitidos por la crítica especializada en el proceso de recepción de los textos carrionianos. En la obra se pudo colegiar que el simbolismo de la imago mujer se construye basado en un eje de oposición binaria, cuya matriz simbólica converge con la caracterización del arquetipo de la Diosa Madre.

Este diseño de los personajes femeninos, integrado al mito del andrógino, fue examinado desde un enfoque icónico como procedimiento práctico del análisis semiótico. Dicho enfoque tuvo en cuenta el paralelismo de la exégesis narrativa del mito con el simbolismo del sexto arcano del Tarot, y en correspondencia con las claves narrativas imbricadas. Quedaron demostradas las relaciones entre las variantes de ficcionalización de este intertexto mitopoético con las ideas filosóficas positivistas del existencialismo nietzscheano, transparentadas por Carrión no sólo en su prosa imaginativa, sino también en trabajos periodísticos sobre política, ciencia y máximas filosóficas. Lo anterior posibilitó comprender cómo su visión cosmogónica del mundo, basada en el determinismo mecanicista de las leyes naturales, rectoras de la actividad humana, su sentido anticlerical y su postura pesimista ante el desarrollo de la vida social, económica y política cubanas, perfilaron las situaciones, motivos y representaciones simbólicas de sus personajes.

De esta manera, este estudio contribuye a la investigación de los mitos en obras de la literatura cubana, en particular al examen del componente mítico asociado a la mujer, tópico de interés para diversos analistas en los últimos años. Desde esta arista epistemológica, este estudio también responde a los reclamos efectuados por los especialistas en torno a la necesidad de revaluar el legado histórico-literario de autores cubanos, en particular de Miguel de Carrión, teniendo en cuenta perspectivas de acercamiento sustentadas por teorías más contemporáneas. El carácter generalizador de los postulados teóricos aquí aplicados aporta una herramienta efectiva, útil para futuras investigaciones relacionadas con la temática, dada la influencia del mito en los más variados géneros literarios, en particular en la narrativa.

\section{OBRAS CITADAS}

Álvarez Álvarez, Luis. 2010. El arte de investigar el arte. Santiago de Cuba: Editorial Oriente. Aun Weor, Samael. 2006. Tarot y Kábala. Recuperado en marzo del 2012, de http://es.scribd. com/doc/6662759/Weor-Samael-Tarot-y-Kabala

Barcia, María del Carmen. 2009. Capas populares y modernidad en Cuba (1878-1930). La Habana: Editorial de Ciencias Sociales.

Boeree, George. 2012. "Teorías de la personalidad. Carl Jung 1875-1961". Traducción de Rafael Gaultier. Recuperado en marzo del 2012, de http://www.psicologia-online.com/ ebooks/personalidad/jung.htm

Campbell, Joseph. 1959. El héroe de las mil caras. Psicoanálisis del mito. México D.F.: Fondo de Cultura Económica. 
Carrión, Miguel de. 1903. "La ley del divorcio III. La evolución biológica social”. Azul y Rojo 2.17: 14 .

. 1910. "Pulsando a la patria. Actual situación política de Cuba y sus consecuencias para el porvenir". Letras VI.24: 2.

. 1976. El milagro y la esfinge. La Habana: Editorial Arte y Literatura. . 1978. Las honradas y las impuras. La Habana: Editorial Letras Cubanas.

Chevalier, Jean. 1986. Diccionario de símbolos. Barcelona: Editorial Herder.

Cooper, J. 1998. Cuentos de hadas. Alegorías de los mundos internos. Buenos Aires: Editorial Sirio.

Encausse, Gerard (Papus). 2006. El tarot de los bohemios. Parte 2. Recuperado en mayo del 2006, de http://www.megaupload.com/?d=K234UHE7

Pereira Torres, Mercedes. 1978. "Prólogo". En de Carrión, Miguel, Las honradas y Las impuras. La Habana: Editorial Letras Cubanas. 5-39.

Romero, Cira (Comp.). 2011. "Una novela nietzscheana”. En Varona, Enrique José, Escala de varia intención. Selección de textos. La Habana: Letras Cubanas. 367-369.

. 2003. "La obra novelística de M. de Carrión y C. Loveira". En Portuondo, José Antonio (Dir.), Historia de la literatura cubana. Tomo II. La literatura cubana entre 1899 y 1958. La República. La Habana: Editorial Letras Cubanas. 139-145. 